\title{
Mechanochemical Syntheses of Isostructural Luminescent Cocrystals of 9-Anthracenecarboxylic Acid with two Dipyridines Coformers
}

\author{
Torvid Feiler ${ }^{1}$, Biswajit Bhattacharya ${ }^{1, *}$, Adam A. L. Michalchuk ${ }^{1}$, Vincent Schröder ${ }^{2,3}{ }^{10}$, \\ Emil List-Kratochvil ${ }^{2,3}$ and Franziska Emmerling 1,4,*(D) \\ 1 BAM Federal Institute for Materials Research and Testing, Richard-Willstätter-Str 11, 12489 Berlin, Germany; \\ torvid.feiler@bam.de (T.F.); adam.michalchuk@bam.de (A.A.L.M.) \\ 2 Department of Chemistry, Department of Physics, Humboldt-Universität zu Berlin, IRIS Adlershof, \\ Brook-Taylor-Straße 6, 12489 Berlin, Germany; vincent.schroeder@helmholtz-berlin.de (V.S.); \\ emil.list-kratochvil@hu-berlin.de (E.L.-K.) \\ 3 Helmholtz-Zentrum Berlin für Materialien und Energie GmbH, Brook-Taylor-Straße 6, \\ 12489 Berlin, Germany \\ 4 Department of Chemistry, Humboldt-Universität zu Berlin, Brook-Taylor-Str. 2, 12489 Berlin, Germany \\ * Correspondence: Biswajit.Bhattacharya@bam.de (B.B.); franziska.emmerling@bam.de (F.E.)
}

Received: 6 September 2020; Accepted: 25 September 2020; Published: 1 October 2020

\begin{abstract}
Tuning and controlling the solid-state photophysical properties of organic luminophore are very important to develop next-generation organic luminescent materials. With the aim of discovering new functional luminescent materials, new cocrystals of 9-anthracene carboxylic acid (ACA) were prepared with two different dipyridine coformers: 1,2-bis(4-pyridyl)ethylene and 1,2-bis(4-pyridyl)ethane. The cocrystals were successfully obtained by both mechanochemical approaches and conventional solvent crystallization. The newly obtained crystalline solids were characterized thoroughly using a combination of single crystal X-ray diffraction, powder X-ray diffraction, Fourier-transform infrared spectroscopy, differential thermal analysis, and thermogravimetric analysis. Structural analysis revealed that the cocrystals are isostructural, exhibiting two-fold interpenetrated hydrogen bonded networks. While the $\mathrm{O}-\mathrm{H} \cdots \mathrm{N}$ hydrogen bonds adopts a primary role in the stabilization of the cocrystal phases, the $\mathrm{C}-\mathrm{H} \cdots \mathrm{O}$ hydrogen bonding interactions appear to play a significant role in guiding the three-dimensional assembly. Both $\pi \cdots \pi$ and $\mathrm{C}-\mathrm{H} \cdots \pi$ interactions assist in stabilizing the interpenetrated structure. The photoluminescence properties of both the starting materials and cocrystals were examined in their solid states. All the cocrystals display tunable photophysical properties as compared to pure ACA. Density functional theory simulations suggest that the modified optical properties result from charge transfers between the ACA and coformer molecules in each case. This study demonstrates the potential of crystal engineering to design solid-state luminescence switching materials through cocrystallization.
\end{abstract}

Keywords: cocrystal; mechanochemical synthesis; X-ray diffraction; photoluminescence properties; DFT calculation

\section{Introduction}

Organic solid-state luminescent materials have been studied widely over the last decade [1-3]. This attention owes to their appealing and versatile optoelectronic applications in the fields of laser technology [4], chemical/biological sensors [5], and for organic light-emitting diodes [6]. The bulk fluorescent properties of solids are well-known to depend on the primary molecular structure of the individual components. Moreover, solid-state fluorescence properties are also influenced 
by intermolecular interactions or stacking patterns of the molecules in the crystal structure [7-9]. A plethora of pure organic solid-state chromophores with controllable emission properties have been reported $[10,11]$. To date, however, technology to selectively obtain light emissions of a desired wavelength remains an exceptional challenge. Correspondingly, new approaches are needed to switch and tune the emission wavelength of organic chromophores to meet the needs of next-generation light-emitting materials. In this context, cocrystallization has become a popular tool. In this approach, two or more different molecules are crystallized together within the same crystal structure, interacting through various noncovalent interactions, including hydrogen and halogen bonds, $\mathrm{C}-\mathrm{H} \cdots \pi, \pi \cdots \pi$, and charge-transfer (CT) interactions [12-14]. The cocrystal solid forms often exhibit entirely new-or greatly enhanced-physicochemical properties, as compared to the pure parent materials [15-19]. Yan and co-workers demonstrated multi-color emissions, as well as strong two-photon luminescence by the cocrystallization of various coformers with a stilbene derivative, 1,4-bis-p-cyanostyrylbenzene [20]. Enhancement of the luminescence efficiency of 1,3,6,8-tetramethylpyrene:perylene cocrystals was shown by Liu et al [21]. The authors ascribed the improved efficiency to the effective energy transfer. In other cases, such as in cocrystals of 2,6-biphenyl-4-pyrone with different carboxylic acids, the luminescent properties of the luminophore could be completely altered [22].

Traditionally, cocrystals are prepared using solution-based evaporative methods. These methods suffer from solubility issues (e.g., where individual components have different solubility) and scale up [23,24]. Environmentally friendly alternatives have instead been developed based on mechanochemical technologies. These mechanochemical techniques facilitate the rapid and high-yielding synthesis of a broad range of molecules and materials, including multi-component solids, porous materials, and biomolecules [25-29]. The wide reach and sustainability of mechanochemistry led to it being dubbed one of the " 10 innovations that will change the world" by the International Union of Pure and Applied Chemistry (IUPAC) in 2019 [30]. Neat grinding of two or more components signifies the simplest case of mechanochemical cocrystallization $[25,26]$. Often, neat grinding does not allow quantitative yields. It is therefore more common to add catalytic quantities of liquid to mechanochemical transformations, referred to as liquid-assisted grinding (LAG). The small addition of a liquid can greatly accelerate the transformation and yield $[25,26]$. LAG methods have been widely used for preparing pharmaceutical cocrystals [31], although their application for the preparation of fluorescent cocrystals remains uncommon [32].

Here, we chose 9-anthracenecarboxylic acid (ACA) as a photoactive building block for cocrystallization due to its unique optical and electronic properties. By selecting suitable coformers with potential hydrogen bond interactions with the carboxylic acid group in ACA (Scheme 1), two new isostructural cocrystals were obtained by mechanochemical reactions. The applied dipyridine linkers here are widely employed for the design of molecular materials, as well as functional coordination complexes [33,34] and coordination framework compounds [35-38]. Both multicomponent solids were characterized by experimental methods. A thorough investigation of the cocrystal fluorescent properties and density functional theory (DFT) calculations of the band structure and fluorescent properties of both cocrystals, along with ACA, describe how cocrystallization can alter the photoluminescence emission of pure fluorophore. The method opens the door to design and develop a new type of multicomponent solid with excellent optical properties. 
<smiles>O=C(O)c1c2ccccc2cc2ccccc12</smiles>

9-Anthracenecarboxylic acid (ACA)

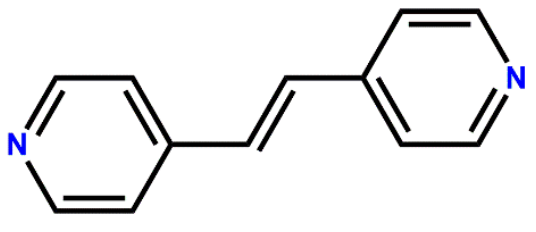

1,2-Bis(4-pyridyl)ethylene (BPEE)

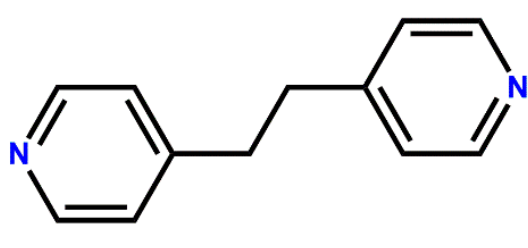

1,2-Bis(4-pyridyl)ethane (BPE)

Scheme 1. Molecular structures of 9-anthracenecarboxylic acid (ACA) and different dipyridines coformers in the present study.

\section{Experimental Section}

\subsection{Materials}

1,2-Bis(4-pyridyl)ethane (98.0\%) and 1,2-di(4-pyridyl)ethylene (96\%) were purchased from J\&K (Lommel, Belgium). 9-Anthracenecarboxylic acid (95\%) was purchased from Fluoro Chem (Hadfield, UK). All chemicals were used as obtained, without further purification.

\subsection{Preparation of the Cocrystals via Ball Mill}

Ball mill grinding. All mechanochemical reactions were performed using a vibration ball mill (Pulverisette 23, Fritsch, Idar-Oberstein, Germany). The materials were place in a 10-mL stainless steel vessel along with two 10-mm stainless steel milling balls. System-specific details are given below:

ACA-1,2-Bis(4-pyridyl)ethylene (BPEE) (2:1) cocrystal (1). ACA (444 mg, $2 \mathrm{mmol}$ ) and BPEE $(182 \mathrm{mg}, 1 \mathrm{mmol}$ ) in a 2:1 stoichiometric ratio was taken into a grinding jar (steel, $10 \mathrm{~mL}$ ), along with two stainless steel balls $(10 \mathrm{~mm}, 4 \mathrm{~g})$ with additional methanol $(80 \mu \mathrm{L})$. The resulting mixture was milled at $50 \mathrm{~Hz}$ for either 5 or $30 \mathrm{~min}$, as described in the main text.

ACA-1,2-Bis(4-pyridyl)ethane (BPE) (2:1) cocrystal (2). ACA-BPE cocrystal was synthesized by the same LAG method as that for the ACA-BPEE cocrystal using $1 \mathrm{mmol}$ of BPE (184 mg) instead of BPEE.

Following ball milling, the resulting powders were analyzed immediately by powder X-ray diffraction.

\subsection{Preparation of Single Crystals of the Cocrystals}

ACA (222 mg, $1 \mathrm{mmol}$ ) and BPEE (91 mg, $0.5 \mathrm{mmol})$ or BPE (92 mg, $0.5 \mathrm{mmol})$ in a 2:1 stoichiometric ratio were ground in a mortar with a few drops of $\mathrm{MeOH}$ for about $5 \mathrm{~min}$. This procedure was repeated three times. The dry powder was subsequently dissolved in hot methanol $\left(45^{\circ} \mathrm{C}, 25 \mathrm{~mL}\right)$ and left to crystallize. Following approximately 4 days, block-shaped single crystals of both cocrystals were harvested and analyzed by single-crystal $\mathrm{X}$-ray diffraction. Elemental analysis: ACA-BPEE cocrystal (1), Anal. Calcd. (\%): C, 80.50; N, 4.82; H, 4.47. Found: C, 80.36; N, 4.97; H, 4.27. ACA-BPE cocrystal (2), Anal. Calcd. (\%): C, 80.24; N, 5.13; H, 4.46. Found: C, 80.49; N, 4.96; H, 4.72. 


\subsection{Analytical Methods}

\subsubsection{Single-Crystal X-ray Diffraction (SCXRD)}

SCXRD data for each cocrystal product were collected using a Bruker D8 Venture diffractometer (Bruker AXS, Karlsruhe, Germany) equipped with graphite-monochromated Mo K $\alpha$ radiation $(\lambda=0.71073 \AA)$. Data reduction was performed using the Bruker AXS SAINT [39] and SADABS [40] software packages. Each structure was solved through the use of SHELXS 2018 [41] using the direct method, followed by successive Fourier and difference Fourier synthesis. Full-matrix least-squares refinements were done on F2 using SHELXL 2018 [41], including anisotropic displacement parameters for all nonhydrogen atoms. During refinement of the ACA-BPE cocrystal, disorder of the carbon atoms (C12A and C12B) of BPE exhibited disorder; their occupancies were therefore fixed each at 0.50, before final refinement. Hydrogen atoms directly bonded to oxygen were located from the electron density maps, and all the hydrogen atoms bonded directly to carbon were fixed at their ideal positions. All additional calculations were performed within the SHELXS 2018, SHELXL 2018, and WinGX (Ver. 1.80) [42] software suites. Mercury v3.6 [43] was used to visualize and display structural figures. Data collection, structure refinement parameters, and crystallographic data of the cocrystals are summarized in Table 1.

Table 1. Crystallographic and structural refinement parameters of 9-anthracene carboxylic acid-1,2-bis(4-pyridyl)ethylene (ACA-BPEE) and ACA-1,2-bis(4-pyridyl)ethane (BPE) cocrystals.

\begin{tabular}{|c|c|c|}
\hline Compound Name & ACA-BPEE (1) & ACA-BPE (2) \\
\hline Temperature/K & 150 & 150 \\
\hline Formula & $\mathrm{C}_{21} \mathrm{H}_{15} \mathrm{O}_{2} \mathrm{~N}$ & $\mathrm{C}_{21} \mathrm{H}_{16} \mathrm{O}_{2} \mathrm{~N}$ \\
\hline Formula Weight & 313.34 & 314.35 \\
\hline Crystal System & Monoclinic & Monoclinic \\
\hline Space group & $\mathrm{C} 2 / \mathrm{c}$ & $\mathrm{C} 2 / \mathrm{c}$ \\
\hline$a / \AA$ & 23.9052(11) & $23.7683(10)$ \\
\hline$b / \AA$ & $9.9355(4)$ & $10.1119(5)$ \\
\hline$c / \AA$ & 13.0565(5) & $13.0879(6)$ \\
\hline$\alpha /^{\circ}$ & 90 & 90 \\
\hline$\beta /^{\circ}$ & $93.704(2)$ & $93.773(2)$ \\
\hline$\gamma /{ }^{\circ}$ & 90 & 90 \\
\hline$V / \AA^{3}$ & $3094.6(2)$ & $3138.8(2)$ \\
\hline Z & 8 & 8 \\
\hline$D_{\mathrm{c}} / \mathrm{g} \mathrm{cm}^{-3}$ & 1.345 & 1.322 \\
\hline$\mu / \mathrm{mm}^{-1}$ & 0.087 & 0.085 \\
\hline$F(000)$ & 1312 & 1304 \\
\hline$\theta$ range $/^{\circ}$ & $2.2-26.8$ & $2.2-26.8$ \\
\hline Reflections collected & 40,599 & 29,294 \\
\hline Unique reflections & 3310 & 3357 \\
\hline Reflections $I>2 \sigma(\mathrm{I})$ & 2845 & 2331 \\
\hline$R_{\text {int }}$ & 0.039 & 0.094 \\
\hline Data/restraints/parameters & $3310 / 0 / 218$ & $3357 / 0 / 226$ \\
\hline Goodness of fit $\left(F^{2}\right)$ & 1.09 & 1.05 \\
\hline
\end{tabular}


Table 1. Cont.

\begin{tabular}{ccc}
\hline Compound Name & ACA-BPEE (1) & ACA-BPE (2) \\
\hline$R 1(I>2 \sigma(\mathrm{I}))$ & 0.0415 & 0.0597 \\
\hline$w R 2(I>2 \sigma(\mathrm{I}))$ & 0.1293 & 0.1572 \\
\hline CCDC No. & 1971303 & 1971304 \\
\hline
\end{tabular}

\subsubsection{Powder X-ray Diffraction (PXRD)}

Prior to analysis, samples of BPEE and BPE were individually ground and packed into borosilicate capillaries (inner diameter $0.5 \mathrm{~mm}$ ). PXRD data were collected from these capillary samples on a Bruker D8 Discover diffractometer (Bruker AXS, Karlsruhe, Germany) equipped with a LYNXEYE XE detector and $\mathrm{Cu}-\mathrm{K}_{\alpha 1}$ radiation $(\lambda=1.506 \AA)$. Data were collected over a range of $2 \theta=5^{\circ}$ to $60^{\circ}$ with step size of $0.009^{\circ}$. The time per step was $2.3 \mathrm{~s}$. A ground sample of ACA was measured using a D8 Advanced diffractometer (Bruker AXS, Karlsruhe, Germany) in Bragg-Brentano geometry equipped with a LYNXEYE XE-T detector and a copper anode $\left(\mathrm{Cu}-\mathrm{K}_{\alpha}, \lambda=1.5406 \AA\right)$. Data were collected over scattering angles $2 \theta=5^{\circ}$ to $80^{\circ}$ with step size $0.02^{\circ}$ and $2 \mathrm{~s}$ per step. PXRD patterns were collected for all cocrystals between 4 and $40^{\circ}$ with a step size of $0.02^{\circ}$ and an accumulation time of $1 \mathrm{~s}$ per step.

\subsubsection{Elemental Analyses}

Carbon, hydrogen, and nitrogen analyses were performed using a Perkin-Elmer (Rodgau, Germany) 240C elemental analyzer.

\subsubsection{Fourier-Transform Infrared Spectroscopy (FTIR)}

FTIR spectra for powdered samples of each material were measured using a Nicolet FT-IR NEXUS (Thermo Fischer, Dreieich, Germnay) spectrometer equipped with a Diamond-ATR-Golden Gate unit and a DTGS KBr detector. Each spectrum was collected across a range of $200-4000 \mathrm{~cm}^{-1}$ with a spectral resolution of $4 \mathrm{~cm}^{-1}$.

\subsubsection{Raman}

Raman spectra were recorded on a $\mathrm{RXN1} 1^{\mathrm{TM}}$ analyzer (Endress+Hauser Process Analysis, Saint-Priest, France) with an excitation wavelength of $\lambda=785 \mathrm{~nm}$. For the measurements, a con-contact probe head with the working distance of $10 \mathrm{~mm}$ and a spot size of $1 \mathrm{~mm}$ was used.

\subsubsection{Thermal Analysis (Differential Thermal Analysis-Thermogravimetric (DTA-TG))}

A simultaneous DTA-TG analysis was conducted using a TAG24 thermoscale (Setaram, Mougins, France). Measurements were performed in open platinum crucibles under continuous Ar-air flow. Measurements were conducted at a heating rate of $10 \mathrm{~K} / \mathrm{min} 25^{\circ}$ to $500^{\circ}$.

\subsubsection{Photoluminescence Spectroscopy}

Photoluminescence measurements were performed with an Edinburgh Instruments (Livingston, UK) FLS 980 fluorescence spectrometer. All photoluminescence spectra were measured in an integrating sphere. The samples were excited with a 450-W ozone-free xenon arc lamp. The detector was a R928P PMT, electrically cooled to $-20^{\circ} \mathrm{C}$.

\subsubsection{Computational Methods}

Initial structures were taken from experimentally determined X-ray diffraction data, as described above. Plane wave density functional theory (pw-DFT) calculations were performed using Quantum ESPRESSO v6.4. [44,45]. Structure relaxation was performed using the exchange-correlation functional of Perdew-Burke-Ernzerhof (PBE) [46] with the exchange-dipole moment (XDM) [47] dispersion 
correction and damping parameters $\mathrm{a}_{1}=0.3275$ and $\mathrm{a}_{2}=2.27673$. Using the projector augmented-wave method, the electronic wave function was expanded in plane waves to a kinetic energy cut-off of 60 Ry for the wave function and $400 \mathrm{Ry}$ for the charge density. Convergence of the electronic wave function was accepted $<10^{-8} \mathrm{Ry}$, and forces were considered as converged when $<10^{-3} \mathrm{Ry} / \mathrm{a}$.u. The electronic band structures were subsequently calculated at the relaxed geometries using the screened hybrid functional HSE06 [48]. The electronic density of the states was plotted across no fewer than $200 k$-points for each cocrystal.

Time-dependent density functional theory (TD-DFT) calculations were performed using Orca v4.2. [49]. All atoms were modeled at the B3LYP/def2-TZVP level. The resolution of identify approximation with def2/J auxiliary basis sets was used for the Coulomb integrals and COSX numerical integration for the Hartree-Fock exchange [50,51]. The asymmetric unit was extracted from the relaxed crystal structures, which was used to calculate the initial excitation energies. The interaction geometry between the dimers was fixed across the hydrogen bonding interactions, followed by relaxation of the dimer on the first singlet excited state potential energy surfaces. The vertical excitation energies were calculated in the relaxed state and taken as indicative of the photoluminescence output. Hydrogen bonding interaction energies were calculated within the framework of the symmetry adapted perturbation theory (SAPT), as implemented in PSI4 [52]. The "bronze-level" SAPT method was selected, as identified by Parker et al. [53]: sSAPT0/jun-cc-PVDZ. This method yields an error of $c a$ $2.97 \mathrm{~kJ} / \mathrm{mol}$ for hydrogen-bonded systems.

\section{Result and Discussion}

9-Anthracenecarboxylic acid (ACA) was screened for new multicomponent fluorescent solids with two different dipyridine coformers, 1,2-bis(4-pyridyl)ethylene (ACA-BPEE 1) and 1,2-bis(4-pyridyl)ethane (ACA-BPE 2). The screening was performed by mechanochemical reaction. Single crystals were grown by dissolving the ground powder in hot methanol. Both solids were obtained in quantitative yields, and their formation was substantiated by X-ray diffraction and spectroscopic and thermal methods of analyses. Crystallographic parameters are given in Table 1, and hydrogen bond lengths, along with the ORTEP diagrams of both multicomponent solids, are shown in the Supplementary Information.

FTIR and Raman spectra of 1-2 are unique compared to the staring materials, supporting the successful formation of multicomponent solids. Moreover, the spectral similarities shared between the cocrystals suggest both solids share similar hydrogen-bonding patterns (Figures S1-S4 in the Supplementary Materials). In FTIR, the characteristic $v(C=O)$ band of ACA at $1668 \mathrm{~cm}^{-1}$ is blue-shifted to $1697 \mathrm{~cm}^{-1}$ in both the cocrystals (Figures S1 and S2). The Raman bands at 1408 and $1559 \mathrm{~cm}^{-1}$ for ACA, which correspond to C-C and/or ring deformation modes, are shifted in the cocrystals to 1412 and $1561 \mathrm{~cm}^{-1}$, respectively (Figure S3).

\subsection{Crystal Structures of $A C A-B P E E$ (1) and ACA-BPE (2) Cocrystals}

Single-crystal analyses revealed both cocrystals to be isostructural, crystallizing in the monoclinic space group $C 2 / c(Z=8)$. The asymmetric unit for each cocrystal contains one ACA and one-half of a bipyridine molecule, the rest of which is generated by a two-fold axis through the centroid of the ring (Figure S4a for $\mathbf{1}$ and Figure S5a for 2). Each cocrystals is based on discrete three-component supramolecular assembly between two ACA molecules and one bipyridine. These assemblies are sustained by $\mathrm{O}-\mathrm{H} \cdots \mathrm{N}$ hydrogen bonds, i.e., acid-pyridine hetero-synthon $\left(\mathrm{O} \cdots \mathrm{N}(\AA), \theta /{ }^{\circ}: 1\right.$ : 2.5795(15), 175 and 2: 2.566(2), 173; Tables S1 and S2) (Figure 1a for 1 and Figure S6a for 2), with comparable interaction energies for each cocrystal as obtained by SAPT simulations: $31.94 \mathrm{~kJ} / \mathrm{mol}$ (ACA-BPEE) and $34.44 \mathrm{~kJ} / \mathrm{mol}$ (ACA-BPE). These calculated hydrogen-bonding energies are within the error of the sSAPT0 method used here. Each three-component motif interacts with six adjacent motifs via $\mathrm{C}-\mathrm{H} \cdots \mathrm{O}$ interactions $\left(\mathrm{O} \cdots \mathrm{C}(\AA), \theta{ }^{\circ}:\right.$ 1: 3.4692(19), 165 and 3.3583(17), 170 and 2: 3.483(3), 165 and 3.367(3), 172; Tables S1 and S2) (Figure $1 \mathrm{~b}$ for $\mathbf{1}$ and Figure S6b for 2). These interactions extend the structure 
into a 3D network with a large 1D channel along the crystallographic $c$-axis (Figure 1c and S4b for 1 and Figure S5b and S6c for 2). To maximize the packing efficiency, two independent equivalent networks interpenetrate. This results in a two-fold interpenetrating hydrogen-bonded network in both of the cocrystal structures (Figure 1d,e for $\mathbf{1}$ and Figure S6d,e for 2). The other interactions that stabilize this interpenetrating structure are the face-to-face $\pi \cdots \pi(3.54-4.06 \AA$ for 1 and $3.55-4.15 \AA$ for

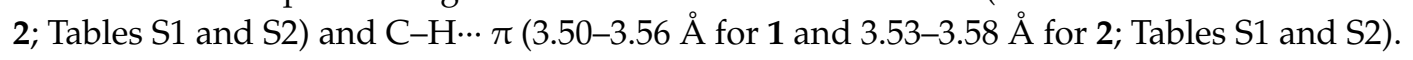
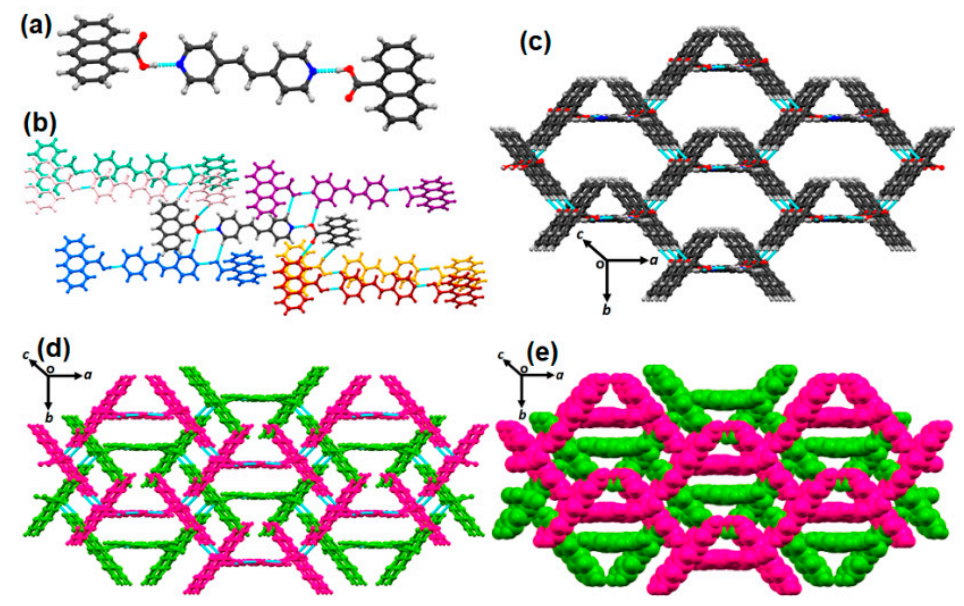

Figure 1. Crystal structure of 9-anthracene carboxylic acid-1,2-bis(4-pyridyl)ethylene (ACA-BPEE): (a) ACA and BPEE molecules form a trimeric motif mediated by acid-pyridine hetero-synthon. (b) Each trimeric motif is connected with six different supramolecular motifs (presented in different colors) by $\mathrm{C}-\mathrm{H} \cdots \mathrm{O}$ interactions. (c) View of a single 3D hydrogen-bonded network showing a large void.

(d,e) Two-fold interpenetrating networks in the ball and stick and space fill models, respectively.

\subsection{Mechanochemical Synthesis}

To synthesize bulk ACA cocrystals, a mechanochemical strategy was employed by both neat grinding (NG), as well as liquid-assisted grinding (LAG), using methanol at $50 \mathrm{~Hz}$ in a vibration ball mill. Mechanochemical syntheses of ACA-BPEE (Figure 2a) and ACA-BPE (Figure 3a) cocrystals resulted in large amounts of the cocrystal phase within 5 min under NG conditions. However, additionally, significant amounts of reactant phases were present for both cocrystals. The reaction was completed after 30 minutes of milling (Figure 2a for ACA-BPEE and Figure 3a for ACA-BPE). For both ACA-BPEE and ACA-BPE, liquid-assisted grinding with methanol resulted in pure cocrystal formation within $5 \mathrm{~min}$ (Figure $2 \mathrm{~b}$ for ACA-BPEE and Figure $3 \mathrm{~b}$ for ACA-BPE). At this time, Bragg reflections related to the reactant phases were no longer visible by PXRD. No changes were observed in the PXRD profiles during the prolonged milling of either ACA-BPEE or ACA-BPE, up to at least 30 min (Figure $2 b$ for ACA-BPEE and Figure $3 b$ for ACA-BPE). The cocrystals therefore appeared stable under the mechanical treatment. Furthermore, the addition of small amounts of methanol led to significant improvements in the reaction time. 

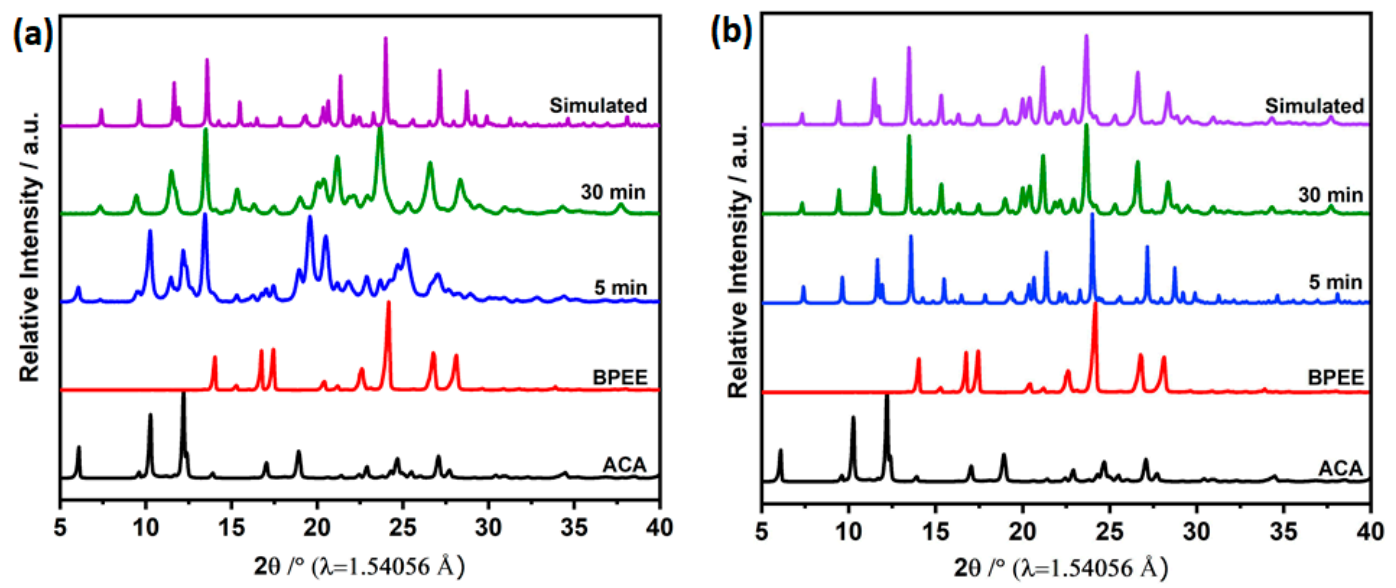

Figure 2. Powder X-ray diffreaction (PXRD) patterns of 9-anthracenecarboxylic acid (ACA), 1,2-bis(4-pyridyl)ethylene (BPEE), and the mechanochemically synthesized ACA-BPEE cocrystal with respect to the different time intervals with (a) neat grinding (NG) and (b) liquid-assisted grinding (LAG) with $\mathrm{MeOH}$.
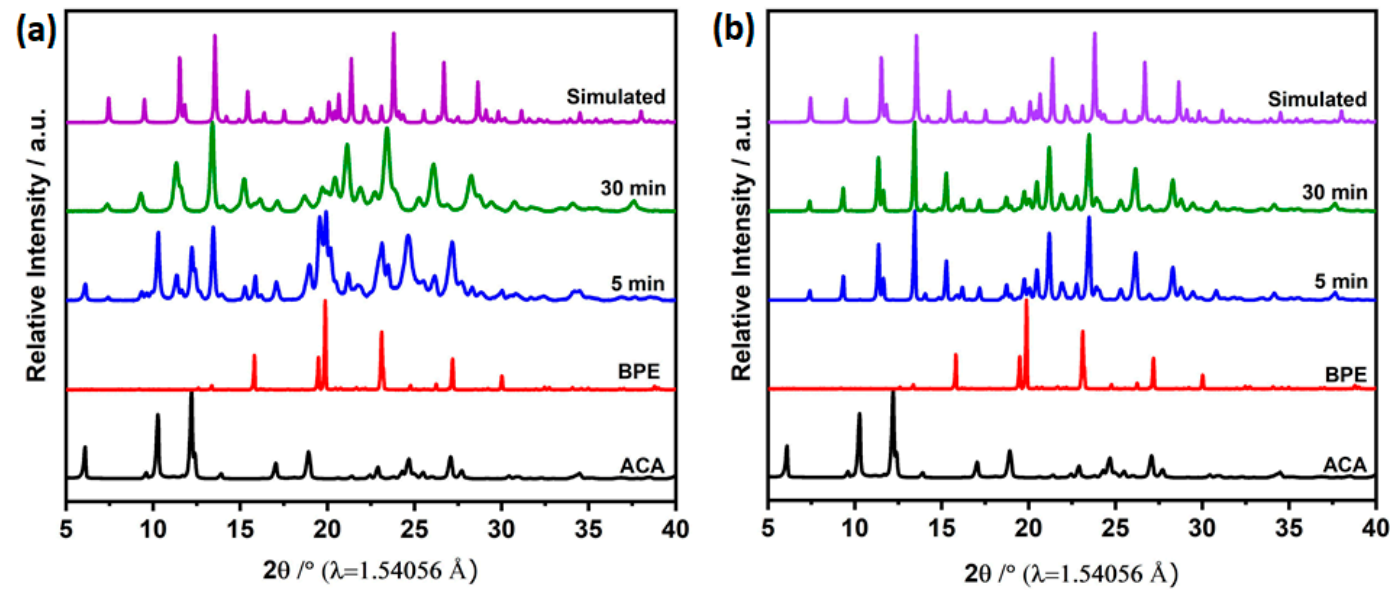

Figure 3. PXRD patterns of 9-anthracenecarboxylic acid (ACA), 1,2-bis(4-pyridyl)ethane (BPE), and the mechanochemically synthesized ACA-BPE cocrystal with respect to different time intervals with (a) neat grinding (NG) and (b) liquid-assisted grinding (LAG) with $\mathrm{MeOH}$.

\subsection{Thermal Analysis}

The thermal behavior of our newly synthesized multicomponent solids was investigated by differential thermal analysis (DTA) with coupled thermogravimetric (TG) analysis (Figure 4). Literature melting points of the pure starting materials are ACA $\left(213-217^{\circ} \mathrm{C}\right)$, BPEE $\left(148-152^{\circ} \mathrm{C}\right)$, and BPE $\left(110-112^{\circ} \mathrm{C}\right)$. The corresponding experimental values obtained in this work are provided in Table S3. The DTA thermograms for both cocrystals exhibit a single well-defined endotherm. This is taken to be the melting point of each material. The DTA thermogram of the ACA-BPEE cocrystal exhibits a sharp endotherm with onset $217^{\circ} \mathrm{C}$ corresponding to the melting, followed by decomposition of the material with a pronounced mass loss shown by the TG scan at ca. $280^{\circ} \mathrm{C}$ (Figure 4a). The ACA-BPE cocrystal exhibits its melting endotherm at $190^{\circ} \mathrm{C}$, followed by decomposition at ca. $270{ }^{\circ} \mathrm{C}$ (Figure $4 \mathrm{~b}$ ). The melting point of ACA-BPE sits between those of the starting materials, whereas ACA-BPEE has virtually the same melting point as ACA (Table S3). In both cocrystals, a negligible weight loss was noticed prior to melting in all TG curves, which clearly indicates that all the multicomponent solids are un-solvated crystal forms. We do note the presence of a broad exotherm in both cocrystals, centered around $c a .65^{\circ} \mathrm{C}$. The origin of this conserved feature is presumably related to the ACA component in all the multicomponent solids (Figure S7). 

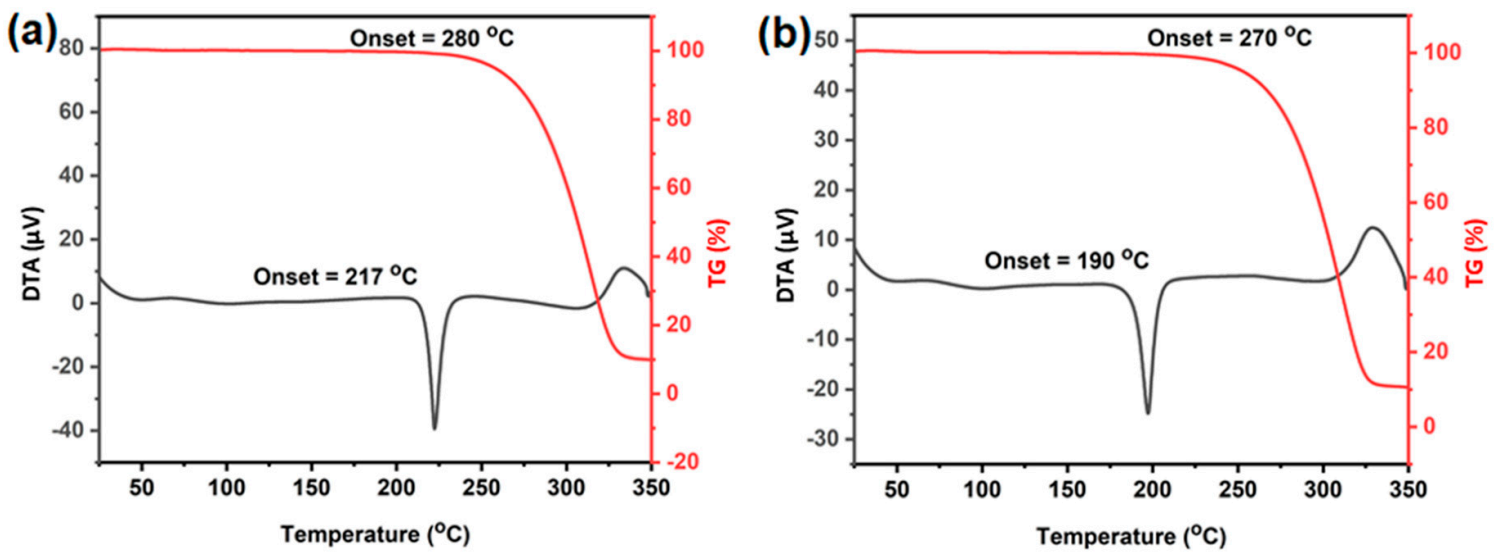

Figure 4. Differential thermal analysis-thermogravimetric (DTA-TG) measurements of (a) ACA-BPEE and (b) ACA-BPE, respectively. The DTA signals (black) of the cocrystal at the onset $217{ }^{\circ} \mathrm{C}$ (for ACA-BPEE) and $190^{\circ} \mathrm{C}$ (for ACA-BPE) can be assigned to the melting of the cocrystals, and after that, the complete mass losses are observed in the TG analysis (red).

\subsection{Luminescent Property}

Altering the crystallographic packing and intermolecular interactions of the organic luminophore can greatly influence the solid-state emission properties of a material. ACA itself is a well-known luminophore, and its luminescent properties were studied in the solution, as well as in the solid-state $[54,55]$. ACA therefore acts as an excellent candidate to study the effects of cocrystallization on luminescent properties.

To collect the photoluminescence spectra (PL), the PL excitation (PLE) spectra for each compound were first measured (Figure S8). The maximum of the PLE spectra was used as the excitation wavelength for the PL emission measurements. In the first instance, the photoluminescence spectra of the coformers and pure ACA were measured, as depicted in Figure 5 and Figure S9. The emission maxima were observed at $509 \mathrm{~nm}\left(\lambda_{\mathrm{ex}}=420 \mathrm{~nm}\right)$ for ACA, $372 \mathrm{~nm}\left(\lambda_{\mathrm{ex}}=340 \mathrm{~nm}\right)$ for BPEE, and $418 \mathrm{~nm}\left(\lambda_{\mathrm{ex}}=355 \mathrm{~nm}\right)$ for BPE. Upon excitation with 450-nm radiation, the ACA-BPEE emission maximum was observed at $492 \mathrm{~nm}$ slightly blue-shifted as compared with ACA (Figure 5). The blue shifts of the emission maxima can be attributed to the H-type aggregation and formation of a robust hydrogen-bonded network in the cocrystal. In the case of the ACA-BPE cocrystal, the emission maximum showed a slight red shift to $518 \mathrm{~nm}\left(\lambda_{\mathrm{ex}}=420 \mathrm{~nm}\right)$ as compared to ACA, presumably due to the absence of conjugation in the BPE molecule (Figure 5). The perceived color of the coformers and the multicomponent solids are displayed on a CIE 1931 diagram (Commission internationale de l'éclairage, Figure S10).

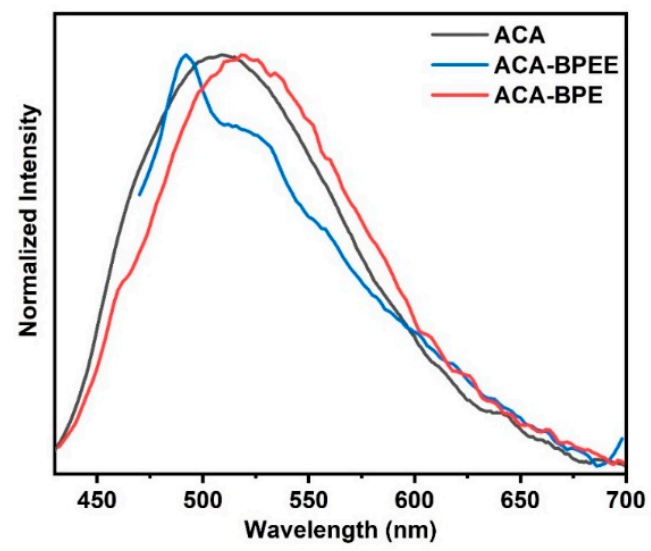

Figure 5. Solid-state photoluminescence spectra of ACA $\left(\lambda_{\mathrm{ex}}=420 \mathrm{~nm}\right), \operatorname{ACA}-\mathrm{BPEE}\left(\lambda_{\mathrm{ex}}=450 \mathrm{~nm}\right)$, and ACA-BPE $\left(\lambda_{\mathrm{ex}}=420 \mathrm{~nm}\right)$. 
To better understand the effect of the coformers and interactions present in the cocrystals on the PL spectra, the electronic structure of each cocrystal was explored within the remit of the DFT. The electronic density of states (DoS) was calculated at the HSE06 level (Figure 6), which is known to reproduce the experimental band gaps well [56]. We note that the ACA excitation in our systems exhibits a band gap of $435 \mathrm{~nm}(2.85 \mathrm{eV})$. Although this is indicative of the fundamental (single-particle) band gap, optical band gaps in molecular crystals typically differ by only a fraction of an eV [57]. Our calculated fundamental gap is in agreement with the excitation energy observed experimentally for ACA $(420 \mathrm{~nm})$, thereby lending support to the validity of the calculations. For both cocrystals, the top of the valence band is composed entirely of ACA-based states. ACA-BPEE exhibits coformer-based states at the bottom of the conduction band, whereas there are mixed ACA and coformer states in the case of ACA-BPE. It follows that direct excitation across the band gap in the former is associated with a charge transfer between the ACA and coformer molecules.

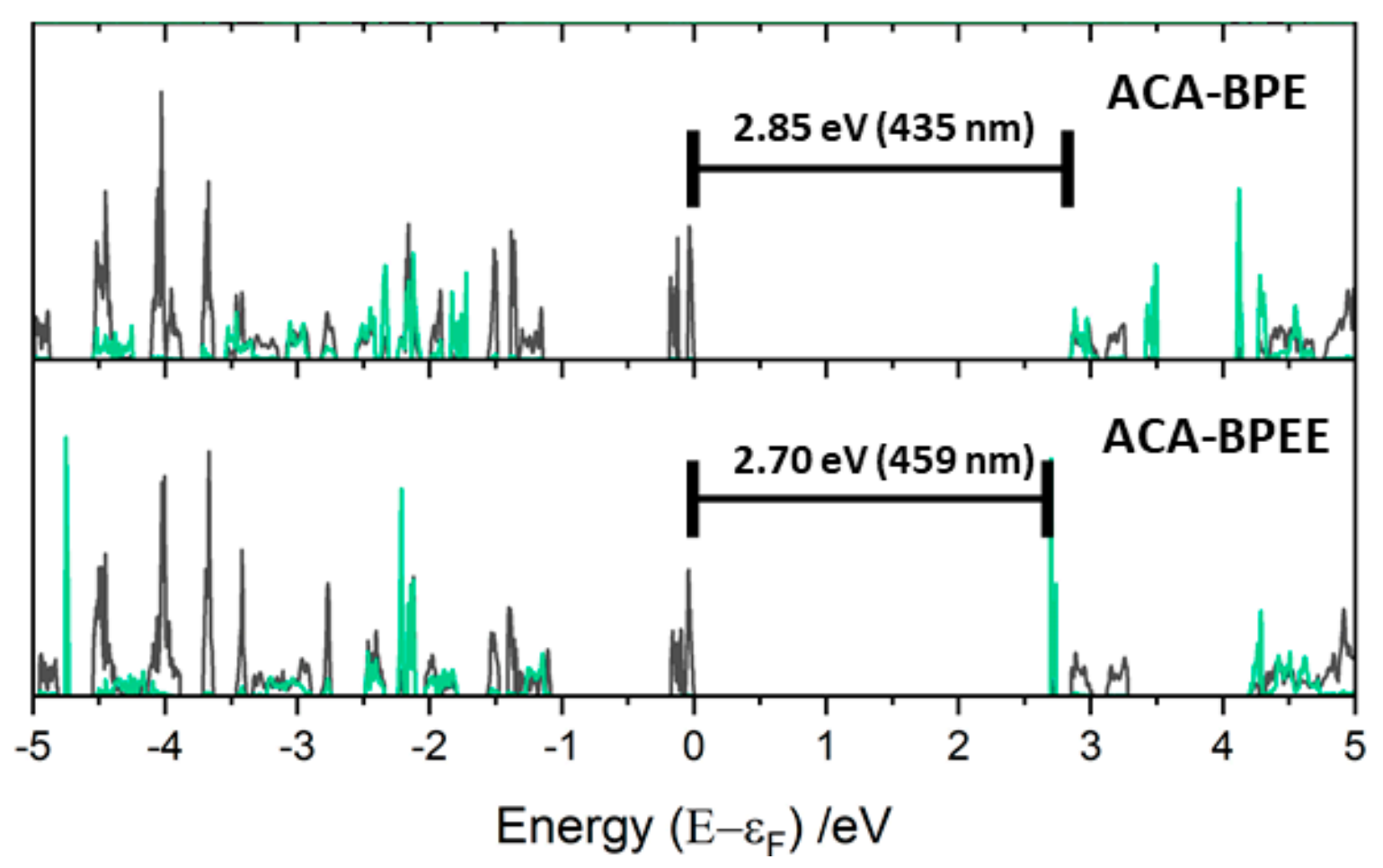

Figure 6. Electronic density of states (DoS) calculated for the ACA-based cocrystals, calculated at the HSE06 level of the theory. For each cocrystal, the projected DoS are shown for ACA (black) and the conformer molecules (green). The band gap is marked in each case.

The PL emission energies cannot occur from relaxation of the single electron states described in Figure 6. To explore this further, the asymmetric unit of the ACA coformer was extracted from the unit cell and modeled using time-dependent DFT calculations.

For each dimer in their crystallographic geometry, the vertical excitation energies were calculated in agreement with the experimental absorption values at the B3LYP/def2-TZVP level of the theory. Moreover, the predicted dimer excitation energy is in agreement with the simulated solid-state band gap and band character in Figure 6, thereby suggesting that the extracted dimers provide a good approximation for the solid-state electronic structure. In each case, the excitation corresponds to a direct excitation of an ACA-based orbital to a conformer-based orbital (Figure 7). This lends support to charge transfer-based excitation in the newly formed cocrystal phases. 
(a)

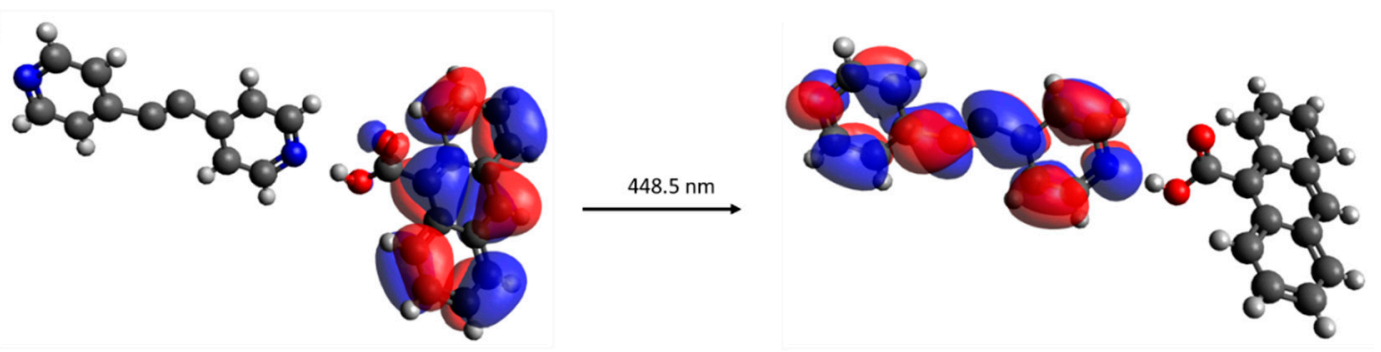

(b)

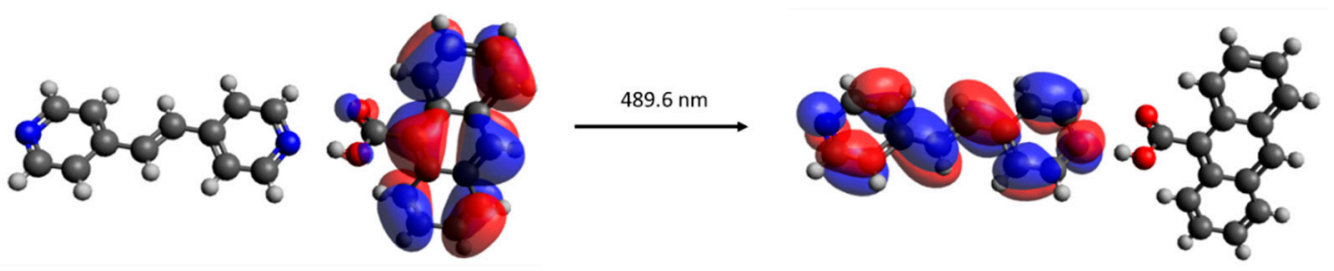

Figure 7. Molecular orbitals associated with the (a) ACA-BPE and (b) ACA-BPEE.

\section{Conclusion}

We herein report two new two-fold interpenetrated isostructural cocrystals of ACA with different dipyridines. Each new cocrystal was prepared by both the mechanochemical and solution methods. The new solids were characterized by SCXRD, thermal analysis (TGA and DTA), PXRD, FTIR, and Raman spectroscopy. Both the cocrystals are sustained by pyridine-carboxylic acid synthons via $\mathrm{O}-\mathrm{H} \cdots \mathrm{N}$ hydrogen bonding to form a three-component supramolecular assembly, and the $\mathrm{C}-\mathrm{H}$... O hydrogen bonds were very vital for guiding the three-dimensional supramolecular assembly. The solid-state emission spectra of these new multicomponent solids signified that their luminescent properties significantly depended on the chemical nature of the coformers. The DFT calculations suggest that these modified luminescent properties are the result of a photo-excited charge transfer between the ACA and conformer molecules. We, therefore, demonstrate how cocrystallization can offer a powerful method to tune the emissions of organic lumiphores and suggest this to be an excellent approach for the design of various new types of organic luminescent materials.

Supplementary Materials: The figures related to the ATR-IR and Raman spectra of the compounds and the structural figures and tables related to the crystal structures reported in this paper, along with the thermal and photoluminescent properties, are available in the supporting materials. CCDC 1971303-1971304 contains the supplementary crystallographic data for this paper in CIF format. These data can be obtained free of charge from The Cambridge Crystallographic Data Centre. The following are available online at http://www.mdpi. com/2073-4352/10/10/889/s1: Figure S1. Comparison of ATR-IR spectra of the ACA, BPEE, and ACA-BPEE cocrystals. Figure S2. Comparison of ATR-IR spectra of the ACA, BPE, and ACA-BPE cocrystals. Figure S3. Raman spectra of the ACA-BPE and ACA-BPEE cocrystals, along with ACA and coformers (BPEE and BPE). Figure S4. Crystal structure of ACA-BPEE (1): (a) Thermal ellipsoid drawing of the asymmetric unit showing atom labels and 50\% probability of the ellipsoids and (b) space filling model of a single 3D hydrogen-bonded network showing a large void. Figure S5. Crystal structure of ACA-BPE (2): (a) Thermal ellipsoid drawing of the asymmetric unit showing atom labels and $50 \%$ probability of the ellipsoids and (b) space filling model of a single 3D hydrogen-bonded network showing a large void. Figure S6. Crystal structure of ACA-BPEE (2): (a) ACA and BPEE molecules form a trimeric motif mediated by acid-pyridine hetero-synthon, and (b) each trimeric motif is connected with six different supramolecular motifs (presented in different colors) by $\mathrm{C}-\mathrm{H}$-... $\mathrm{O}$ interactions. (c) View of a single 3D hydrogen-bonded network showing a large void. (d,e) Two-fold interpenetrating networks in the ball and stick and space fill models, respectively. Table S1. Intermolecular interactions in the crystal structure of the ACA-BPEE cocrystal (1). Table S2. Intermolecular interactions in the crystal structure of the ACA-BPE cocrystal (2). Table S3. Melting points of all the coformers and cocrystals. Figure S7. DTA-TG measurements of 9-anthracenecarboxylic acid (ACA). The DTA (black) and TG (red) traces are shown. The thermal feature with onset at $219^{\circ} \mathrm{C}$ can be assigned to the melting of ACA. Complete mass loss following this melting is observed in the TG analysis. Figure S8. Solid-state photoluminescence excitation (PLE) spectra of (a) $\mathrm{ACA}(\lambda \mathrm{em}=500 \mathrm{~nm}), \operatorname{BPEE}(\lambda \mathrm{em}=370 \mathrm{~nm})$, and ACA-BPEE $(\lambda \mathrm{em}=480 \mathrm{~nm})$ and $(\mathrm{b}) \mathrm{ACA}(\lambda \mathrm{em}=500 \mathrm{~nm})$, $\operatorname{BPE}(\lambda \mathrm{em}=410 \mathrm{~nm})$, and ACA-BPE $(\lambda \mathrm{em}=525 \mathrm{~nm})$. Figure S9. Solid-state photoluminescence spectra of (a) ACA $(\lambda e x=420 \mathrm{~nm}), \operatorname{BPEE}(\lambda \mathrm{ex}=340 \mathrm{~nm})$, and ACA-BPEE $(\lambda \mathrm{ex}=450 \mathrm{~nm})$ and (b) ACA $(\lambda \mathrm{ex}=420 \mathrm{~nm})$, $\mathrm{BPE}(\lambda \mathrm{ex}=355 \mathrm{~nm})$, and ACA-BPE $(\lambda \mathrm{ex}=420 \mathrm{~nm})$. Figure S10. Perceived color by the precursor, and cocrystal photoluminescence emission (S9) displayed in a CIE 1931 diagram. 
Author Contributions: T.F. and B.B. conceived and designed the experiments. T.F. and B.B. synthesized and characterized the compounds. V.S. and E.L.-K. handled the photoluminescent studies. A.A.L.M. performed the computational calculations. B.B. and F.E. supervised the work. All authors have read and agreed to the published version of the manuscript.

Funding: This research was partially funded by the Adolf Martins Postdoctoral Fellowship of BAM (B.B).

Acknowledgments: The authors are grateful to the BAM IT division for the computational resources. We acknowledge Stefan Reinsch for DTA-TG measurements and Max Rautenberg for IR measurements. This work was carried out in the framework of the Joint Lab GEN_FAB and was supported by the HySPRINT Innovation Lab at Helmholtz-Zentrum, Berlin.

Conflicts of Interest: The authors declare no competing financial interests.

\section{References}

1. Chi, Z.; Zhang, X.; Xu, B.; Zhou, X.; Ma, C.; Zhang, Y.; Liu, S.; Xu, J. Recent advances in organic mechanofluorochromic materials. Chem. Soc. Rev. 2012, 41, 3878-3896. [CrossRef] [PubMed]

2. Praveen, V.K.; Vedhanarayanan, B.; Mal, A.; Mishra, R.K.; Ajayaghosh, A. Self-Assembled Extended $\pi$-Systems for Sensing and Security Applications. Acc. Chem. Res. 2020, 53, 496-507. [CrossRef] [PubMed]

3. Martínez-Abadía, M.; Giménez, R.; Ros, M.B. Self-Assembled $\alpha$-Cyanostilbenes for Advanced Functional Materials. Adv. Mater. 2018, 30, 1704161. [CrossRef] [PubMed]

4. Wei, G.-Q.; Wang, X.-D.; Liao, L.-S. Recent Advances in 1D Organic Solid-State Lasers. Adv. Funct. Mater. 2019, 29, 1902981. [CrossRef]

5. Shimizu, M.; Tamagawa, T.; Nishimura, K. 4,5-Diaminophthalimides: Highly efficient solid-state fluorophores and turn-on type fluorescent probes for hydrazine. Mater. Chem. Front. 2019, 3, 563-570. [CrossRef]

6. Butkute, R.; Lygaitis, R.; Mimaite, V.; Gudeika, D.; Volyniuk, D.; Sini, G.; Grazulevicius, J.V. Bipolar highly solid-state luminescent phenanthroimidazole derivatives as materials for blue and white organic light emitting diodes exploiting either monomer, exciplex or electroplex emission. Dye. Pigment. 2017, 146, 425-437. [CrossRef]

7. Anthony, S.P. Polymorph-Dependent Solid-State Fluorescence and Selective Metal-Ion-Sensor Properties of 2-(2-Hydroxyphenyl)-4(3H)-quinazolinone. Chem. Asian J. 2012, 7, 374-379. [CrossRef]

8. Maini, L.; Gallino, F.; Zambianchi, M.; Durso, M.; Gazzano, M.; Rubini, K.; Gentili, D.; Manet, I.; Muccini, M.; Toffanin, S.; et al. Chemical design enables the control of conformational polymorphism in functional 2,3-thieno(bis)imide-ended materials. Chem. Commun. 2015, 51, 2033-2035. [CrossRef]

9. Shi, J.; Yoon, S.-J.; Viani, L.; Park, S.Y.; Milián-Medina, B.; Gierschner, J. Twist-Elasticity-Controlled Crystal Emission in Highly Luminescent Polymorphs of Cyano-Substituted Distyrylbenzene (ßDCS). Adv. Opt. Mater. 2017, 5, 1700340. [CrossRef]

10. Anthony, S.P. Organic Solid-State Fluorescence: Strategies for Generating Switchable and Tunable Fluorescent Materials. ChemPlusChem 2012, 77, 518-531. [CrossRef]

11. Li, E.; Jie, K.; Liu, M.; Sheng, X.; Zhu, W.; Huang, F. Vapochromic crystals: Understanding vapochromism from the perspective of crystal engineering. Chem. Soc. Rev. 2020, 49, 1517-1544. [CrossRef] [PubMed]

12. Aitipamula, S.; Banerjee, R.; Bansal, A.K.; Biradha, K.; Cheney, M.L.; Choudhury, A.R.; Desiraju, G.R.; Dikundwar, A.G.; Dubey, R.; Duggirala, N.; et al. Polymorphs, Salts, and Cocrystals: What's in a Name? Cryst. Growth Des. 2012, 12, 2147-2152. [CrossRef]

13. Tiekink, E. Organic Crystal Engineering: Frontiers in Crystal Engineering; WILEY: New York, NY, USA, 2010.

14. Bond, A.D. What is a co-crystal? CrystEngComm 2007, 9, 833-834. [CrossRef]

15. Harmsen, B.; Leyssens, T. Enabling Enantiopurity: Combining Racemization and Dual-Drug Co-crystal Resolution. Cryst. Growth Des. 2018, 18, 3654-3660. [CrossRef]

16. Martins, I.C.B.; Sardo, M.; Alig, E.; Fink, L.; Schmidt, M.U.; Mafra, L.; Duarte, M.T. Enhancing Adamantylamine Solubility through Salt Formation: Novel Products Studied by X-ray Diffraction and Solid-State NMR. Cryst. Growth Des. 2019, 19, 1860-1873. [CrossRef]

17. Mazzeo, P.P.; Carraro, C.; Monica, A.; Capucci, D.; Pelagatti, P.; Bianchi, F.; Agazzi, S.; Careri, M.; Raio, A.; Carta, M.; et al. Designing a Palette of Cocrystals Based on Essential Oil Constituents for Agricultural Applications. Acs Sustain. Chem. Eng. 2019, 7, 17929-17940. [CrossRef]

18. Sarmah, K.K.; Boro, K.; Arhangelskis, M.; Thakuria, R. Crystal structure landscape of ethenzamide: A physicochemical property study. CrystEngComm 2017, 19, 826-833. [CrossRef] 
19. Kumari, N.; Bhattacharya, B.; Roy, P.; Michalchuk, A.A.L.; Emmerling, F.; Ghosh, A. Enhancing the Pharmaceutical Properties of Pirfenidone by Mechanochemical Cocrystallization. Cryst. Growth Des. 2019, 19, 6482-6492. [CrossRef]

20. Yan, D.; Delori, A.; Lloyd, G.O.; Friščić, T.; Day, G.M.; Jones, W.; Lu, J.; Wei, M.; Evans, D.G.; Duan, X. A Cocrystal Strategy to Tune the Luminescent Properties of Stilbene-Type Organic Solid-State Materials. Angew. Chem. Int. Ed. 2011, 50, 12483-12486. [CrossRef]

21. Li, J.; Takaishi, S.; Fujinuma, N.; Endo, K.; Yamashita, M.; Matsuzaki, H.; Okamoto, H.; Sawabe, K.; Takenobu, T.; Iwasa, Y. Enhancement of luminescence intensity in TMPY/perylene co-single crystals. J. Mater. Chem. 2011, 21, 17662-17666. [CrossRef]

22. Zhou, T.; Jia, T.; Zhao, S.; Guo, J.; Zhang, H.; Wang, Y. Acid-Stimuli-Luminescence and Carbonyl-Proton Interaction Dependent Emission Properties of 2,6-Biphenyl-4-pyrone Crystals. Cryst. Growth Des. 2012, 12, 179-184. [CrossRef]

23. Fischer, F.; Lubjuhn, D.; Greiser, S.; Rademann, K.; Emmerling, F. Supply and Demand in the Ball Mill: Competitive Cocrystal Reactions. Cryst. Growth Des. 2016, 16, 5843-5851. [CrossRef]

24. James, S.L.; Adams, C.J.; Bolm, C.; Braga, D.; Collier, P.; Friščić, T.; Grepioni, F.; Harris, K.D.M.; Hyett, G.; Jones, W.; et al. Mechanochemistry: Opportunities for new and cleaner synthesis. Chem. Soc. Rev. 2012, 41, 413-447. [CrossRef]

25. Braga, D.; Maini, L.; Grepioni, F. Mechanochemical preparation of co-crystals. Chem. Soc. Rev. 2013, 42, 7638-7648. [CrossRef]

26. Friščić, T. New opportunities for materials synthesis using mechanochemistry. J. Mater. Chem. 2010, 20, 7599-7605. [CrossRef]

27. Fischer, F.; Heidrich, A.; Greiser, S.; Benemann, S.; Rademann, K.; Emmerling, F. Polymorphism of Mechanochemically Synthesized Cocrystals: A Case Study. Cryst. Growth Des. 2016, 16, 1701-1707. [CrossRef]

28. Takacs, L. The historical development of mechanochemistry. Chem. Soc. Rev. 2013, 42, 7649-7659. [CrossRef]

29. Zhu, S.-E.; Li, F.; Wang, G.-W. Mechanochemistry of fullerenes and related materials. Chem. Soc. Rev. 2013, 42, 7535-7570. [CrossRef]

30. Gomollón-Bel, F. Ten Chemical Innovations That Will Change Our World: IUPAC identifies emerging technologies in Chemistry with potential to make our planet more sustainable. Chem. Int. 2019, 41, 12. [CrossRef]

31. Tan, D.; Loots, L.; Friščić, T. Towards medicinal mechanochemistry: Evolution of milling from pharmaceutical solid form screening to the synthesis of active pharmaceutical ingredients (APIs). Chem. Commun. 2016, 52, 7760-7781. [CrossRef]

32. Han, L.-L.; Li, Z.-H.; Chen, J.-S.; Wang, X.-P.; Sun, D. Solution and Mechanochemical Syntheses of Two Novel Cocrystals: Ligand Length Modulated Interpenetration of Hydrogen-Bonded 2D 63-hcb Networks Based on a Robust Trimeric Heterosynthon. Cryst. Growth Des. 2014, 14, 1221-1226. [CrossRef]

33. Morelli Frin, K.P.; da Rocha, D.C.; Mamud, J.F.; Polo, A.S. Photoisomerization of di-nuclear rhenium(i) bpe-based compounds. Photochem. Photobiol. Sci. 2018, 17, 1443-1449. [CrossRef]

34. Wang, Y.-G.; Li, Y.-Q.; Tang, H.-H.; Lin, L.-R.; Ma, L.-H. Near-Infrared Photoluminescence and Reversible Trans-to-Cis Photoisomerization of Mononuclear and Binuclear Ytterbium(III) Complexes Functionalized by Azobenzene Groups. ACS Omega 2018, 3, 5480-5490. [CrossRef] [PubMed]

35. Gaur, R. Selective anionic dye adsorption, topology and luminescence study of structurally diverse cadmium(ii) coordination polymers. Inorg. Chem. Front. 2019, 6, 278-286. [CrossRef]

36. Dannenbauer, N.; Matthes, P.R.; Scheller, T.P.; Nitsch, J.; Zottnick, S.H.; Gernert, M.S.; Steffen, A.; Lambert, C.; Müller-Buschbaum, K. Near-Infrared Luminescence and Inner Filter Effects of Lanthanide Coordination Polymers with 1,2-Di(4-pyridyl)ethylene. Inorg. Chem. 2016, 55, 7396-7406. [CrossRef] [PubMed]

37. Podgajny, R.; Chorazy, S.; Nitek, W.; Rams, M.; Bałanda, M.; Sieklucka, B. \{MnII9WV6\}n Nanowires Organized into Three-Dimensional Hybrid Network of I1O2 Topology. Cryst. Growth Des. 2010, 10, 4693-4696. [CrossRef]

38. Muñoz-Lara, F.J.; Gaspar, A.B.; Muñoz, M.C.; Arai, M.; Kitagawa, S.; Ohba, M.; Real, J.A. Sequestering Aromatic Molecules with a Spin-Crossover FeII Microporous Coordination Polymer. Chem. Eur. J. 2012, 18, 8013-8018. [CrossRef]

39. Sheldrick, G. A short history of SHELX. Acta Crystallogr. Sect. A 2008, 64, 112-122. [CrossRef] 
40. Sheldrick, G. SADABS 2.03; University of Göttingen: Göttingen, Germany, 2002.

41. Sheldrick, G. Crystal structure refinement with SHELXL. Acta Crystallogr. Sect. C 2015, 71, 3-8. [CrossRef]

42. Farrugia, L. WinGX suite for small-molecule single-crystal crystallography. J. Appl. Crystallogr. 1999, 32, 837-838. [CrossRef]

43. Macrae, C.; Bruno, I.; Chisholm, J.; Edgington, P.; McCabe, P.; Pidcock, E.; Rodriguez-Monge, L.; Taylor, R.; van de Streek, J.; Wood, P. Mercury CSD 2.0-New features for the visualization and investigation of crystal structures. J. Appl. Cryst. 2008, 41, 466-470. [CrossRef]

44. Giannozzi, P.; Baroni, S.; Bonini, N.; Calandra, M.; Car, R.; Cavazzoni, C.; Ceresoli, D.; Chiarotti, G.L.; Cococcioni, M.; Dabo, I.; et al. QUANTUM ESPRESSO: A modular and open-source software project for quantum simulations of materials. J. Phys. Condens Matter 2009, 21, 395502. [CrossRef] [PubMed]

45. Giannozzi, P.; Andreussi, O.; Brumme, T.; Bunau, O.; Buongiorno Nardelli, M.; Calandra, M.; Car, R.; Cavazzoni, C.; Ceresoli, D.; Cococcioni, M.; et al. Advanced capabilities for materials modelling with Quantum ESPRESSO. J. Phys. Condens Matter 2017, 29, 465901. [CrossRef] [PubMed]

46. Perdew, J.P.; Burke, K.; Ernzerhof, M. Generalized Gradient Approximation Made Simple. Phys. Rev. Lett. 1996, 77, 3865-3868. [CrossRef]

47. Becke, A.D.; Johnson, E.R. Exchange-hole dipole moment and the dispersion interaction. J. Chem. Phys. 2005, 122, 154104. [CrossRef]

48. Krukau, A.V.; Vydrov, O.A.; Izmaylov, A.F.; Scuseria, G.E. Influence of the exchange screening parameter on the performance of screened hybrid functionals. J. Chem. Phys. 2006, 125, 224106. [CrossRef]

49. Neese, F. The ORCA program system. Wires Comput. Mol. Sci. 2012, 2, 73-78. [CrossRef]

50. Kendall, R.A.; Früchtl, H.A. The impact of the resolution of the identity approximate integral method on modern ab initio algorithm development. Theor. Chem. Acc. 1997, 97, 158-163. [CrossRef]

51. Vahtras, O.; Almlöf, J.; Feyereisen, M.W. Integral approximations for LCAO-SCF calculations. Chem. Phys. Lett. 1993, 213, 514-518. [CrossRef]

52. Parrish, R.M.; Burns, L.A.; Smith, D.G.A.; Simmonett, A.C.; DePrince, A.E.; Hohenstein, E.G.; Bozkaya, U.; Sokolov, A.Y.; Di Remigio, R.; Richard, R.M.; et al. Psi4 1.1: An Open-Source Electronic Structure Program Emphasizing Automation, Advanced Libraries, and Interoperability. J. Chem. Theory Comput. 2017, 13, 3185-3197. [CrossRef]

53. Parker, T.M.; Burns, L.A.; Parrish, R.M.; Ryno, A.G.; Sherrill, C.D. Levels of symmetry adapted perturbation theory (SAPT). I. Efficiency and performance for interaction energies. J. Chem. Phys. 2014, 140, 094106. [CrossRef] [PubMed]

54. Zhu, L.; Al-Kaysi, R.O.; Dillon, R.J.; Tham, F.S.; Bardeen, C.J. Crystal Structures and Photophysical Properties of 9-Anthracene Carboxylic Acid Derivatives for Photomechanical Applications. Cryst. Growth Des. 2011, 11, 4975-4983. [CrossRef]

55. Zhu, L.; Tong, F.; Salinas, C.; Al-Muhanna, M.K.; Tham, F.S.; Kisailus, D.; Al-Kaysi, R.O.; Bardeen, C.J. Improved Solid-State Photomechanical Materials by Fluorine Substitution of 9-Anthracene Carboxylic Acid. Chem. Mater. 2014, 26, 6007-6015. [CrossRef]

56. Garza, A.J.; Scuseria, G.E. Predicting Band Gaps with Hybrid Density Functionals. J. Phys. Chem. Lett. 2016, 7, 4165-4170. [CrossRef] [PubMed]

57. Bredas, J.-L. Mind the gap! Mater. Horiz. 2014, 1, 17-19. [CrossRef]

(C) 2020 by the authors. Licensee MDPI, Basel, Switzerland. This article is an open access article distributed under the terms and conditions of the Creative Commons Attribution (CC BY) license (http://creativecommons.org/licenses/by/4.0/). 